\title{
Giant Pericardial Cyst - Eroding Left Ventricle
}

\author{
Shah RK, Jaiswal RK, Pokharel DP \\ *Department of cardiology, NAMS, Bir Hospital, Department of radiology, NAMS, Bir Hospital, Department of cardiothoracic \\ Surgery, NAMS
}

Corresponding: Dr. Ram Kishor Shah

National Academy of Medical Sciences, Bir Hospital P.O.Box. 8011, Kathmandu, Nepal

Email: rkshah40@yahoo.com

\section{Abstract}

\begin{abstract}
Pericardial cyst is the result of an outpuching of the parietal pericardium that is lined by mesothelial cells. They represent $6 \%$ of mediastinal masses, and $33 \%$ of mediastinal cysts. Other cysts in the mediastinum are brochogenic-34\%, enteric- $12 \%$, thymic and others-21\%.A 19 year old man admitted with exertional breathlessness and a typical chest pain. The result of physical examination was within normal linits. Resting 12-lead electrocardiography shows $\mathrm{T}$ inversion in lead 1, AVL, V5 and V6. A posteroanterior chest radiograph revealed a cystic mass in the mediastinum. Transthoracic and transoesophageal echocardiography confirmed the presence of a large fluid filled cyst within the pericardial space. Contrast CT imaging revealed a giant pericardial cyst $(10 \times 10 \times 12 \mathrm{~cm})$ in left cardiophrenic angle, later confirmed intraoperatively and by histopathology. Pericardial cysts occur at the rate of 1 person per 100,000. Seventy five percent of them have no associated symptoms, and are usually found incidentally during routine chest $\mathrm{x}$-ray or echocardiography. Cardiac tamponade, obstruction of right main stem bronchus, and sudden death are the life threatening emergencies that have been reported. The management of pericardial cysts includes observation, percutaneous drain-age, and resection.
\end{abstract}

Keywords : pericardial cysts, left ventricle, echocardiogram, CT scan

\section{INTRODUCTION}

Pericardial cysts is the result of an out pouching of the parietal pericardium that is lined by mesothelial cells. Most of the pericardial cysts are unilocular. They usually contain clear yellow fluid and do not communicate with the pericardial space. Pericardial cyst is an uncommon benign congenital anomaly which is located in the middle mediastinum. They represent $6 \%$ of mediastinal masses, and $33 \%$ of mediastinal cysts. Other cysts in the mediastinum are bronchogenic-34\%, enteric- $12 \%$, thymic and others- $21 \%$. In the middle cysts. Pericardial and bronchogenic cysts share the second most common etiology after lymphomas. The presented case is a symptomatic pericardial cyst.

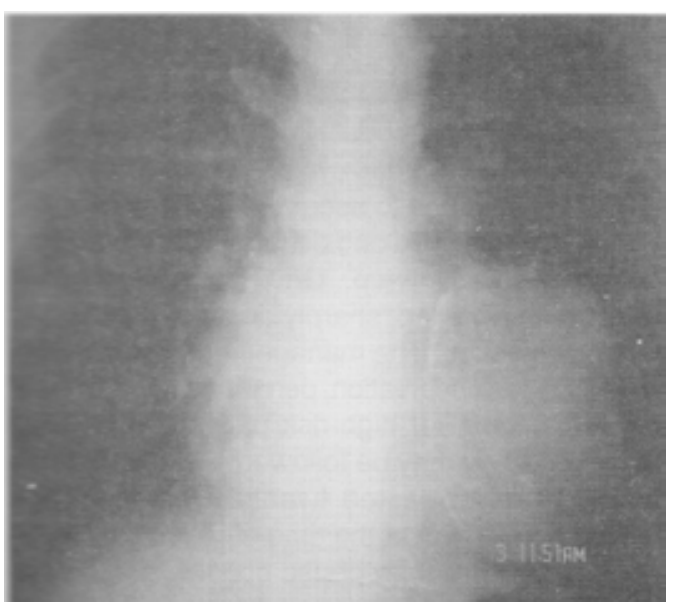

Figure 1: Chest X-ray PA View showing cystic mass in mediastinum

\section{CASE REPORT}

A 19 year old man admitted with exertional breathlessness (New York Heart Association class II) and a typical chest pain. The result of physical examination was within normal limits. A chest radiograph revealed a cystic mass in the mediastinum (Figure 1, 2).

Resting 12 lead electrocardiography showed $T$ inversion in lead I, AVL, V5 and V6.

Transthoracic and transoesophageal echocardiography confirmed the presence of a large fluid filled cyst within the pericardial space(Figure 3)

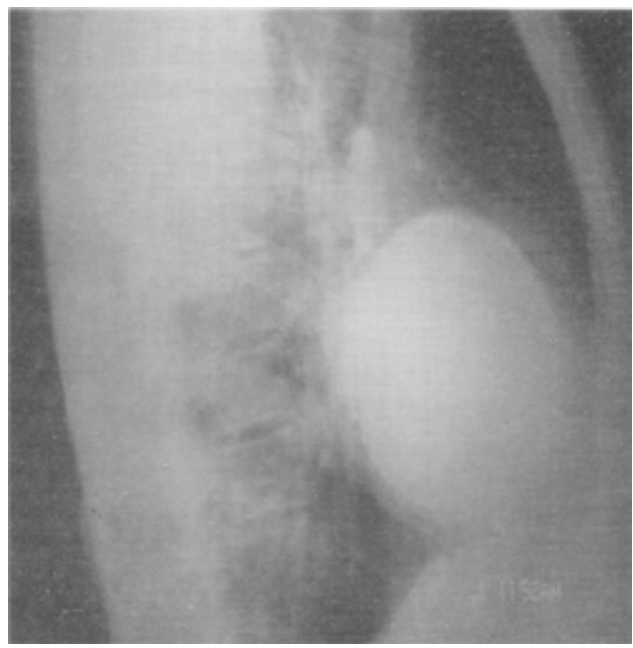

Figure 2: Chest $\mathrm{X}$-ray Left Lateral View showing cystic mass in mediastinum

@Nepalese Heart Journal. Nepalese Heart Journal retains copyright and work is simultaneously licensed under Creative Commons Attribution License CC - BY 4.0 that allows others to share the work with an acknowledgement of the work's authorship and initial publication in this journal. 
Ultrasonogram of Abdomen and pelvis was normal. Contrast CT imaging revealed a giant pericardial cyst $(10 \times 10 \times 12 \mathrm{~cm})$ in left cardiophrenic angle and planned for surgery. (Figure)

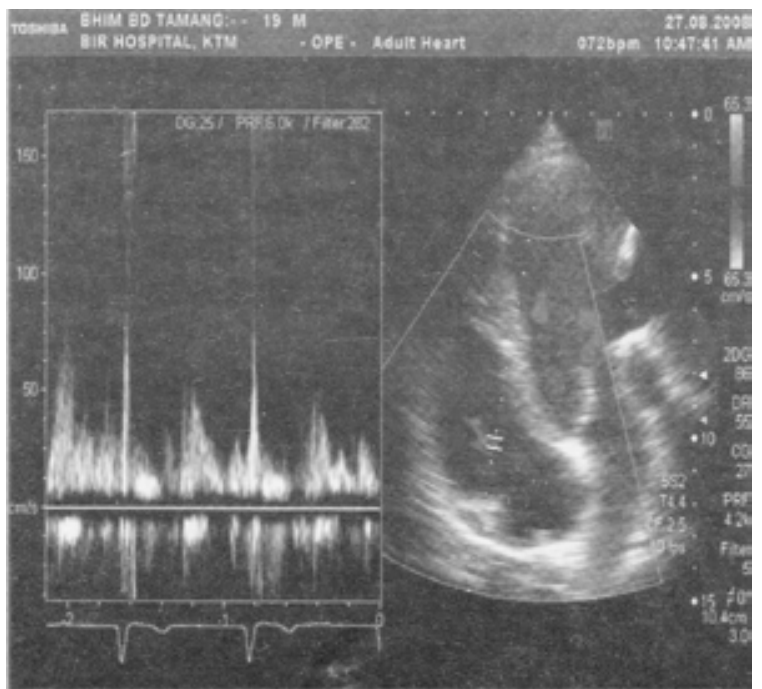

Figure 3: Transthoracic Echocardiogram Showing cyst arising from the pericardium

In the operating room, under general anesthesia left thorax was opened. The cyst was readily visualized at the anterolateral aspect of the left pericardium measuring approximately (10x10 $\mathrm{cm}$ ) eroding left ventricle. The connection between the cyst and the pericardial space was identified \& cystectomy done.

The pathology report confirmed the diagnosis of a benign single layer of mesothelial cells-lined cyst (Figure 5). Accordingly the pre-operative diagnosis was confirmed.

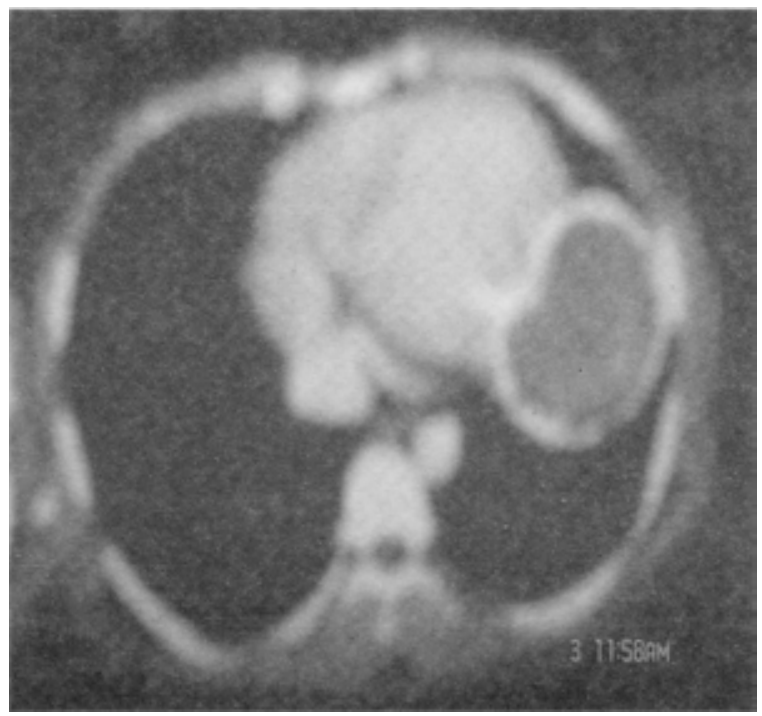

Figure 4: CT Thorax Showing cyst arising from pericardium

\section{DISCUSSION}

Pericardial cysts occur at the rate of 1 person per 100,000 . they are thought toresult from failure of fusion of one of the mesenchymal lacunae that form the pericardial sac. Seventy five percent of them have no associated symptoms, and are usually found incidentally during routin chest $\mathrm{x}$-ray or echocardiography. There have been about twenty reported cases of pericardial cyst presenting before the age of eighteen. Seventy percent of them are located at the right cardiophrenic angle, $22 \%$ in the left, and the rest are in the posterior or anterior superior mediastinum. The size varies from 2 to $28 \mathrm{~cm}$. present, symptoms are usually due to compression of adjacent organs and include atypical chest pain, dyspnea, and persistent cough. Cardiac tamponade, obstruction right main stem bronchus, and sudden death are the life threatening emergencies that have been reported. Cardiac tamponade is usually due to intra-pericardial rupture of the cyst, although tamponade due to spontaneous hemorrhage into the cyst has also been reported. Other reported complications include right ventricular outflow obstruction, inflammation and infection, pulmonary stenosis, partial erosion into adjacent structures, atrial fibrillation, and congestive heart failure. Contrast CT scan has been the modality of choice to diagnose and to follow pericardial cysts. However, no studies have been done to ascertain the superiority of contrast CT over MRI and echocardiography for diagnosis or for follow-up. On CT scan pericardial cysts are thin-walled, sharphy defined, oval homogeneous masses. The management of pericardial cysts includes observation, percutaneous drainage, and resection.

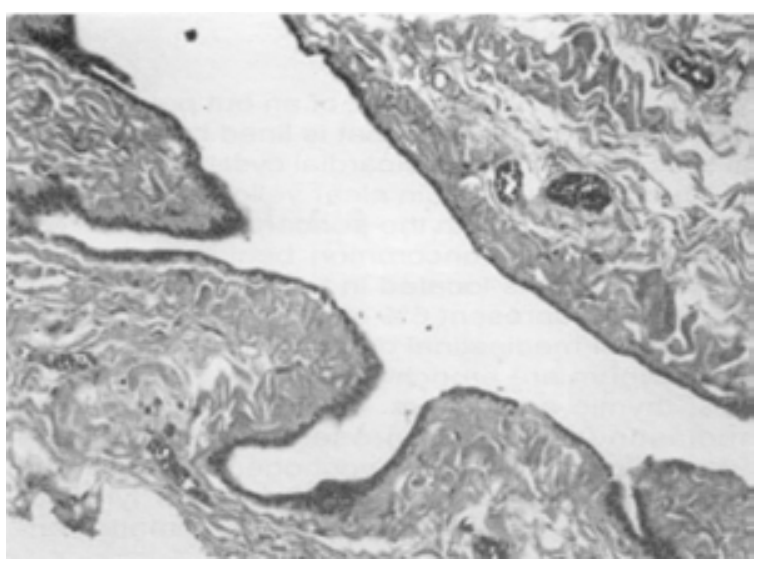

Figure 5: Pericardial cyst: Bening single layer of mesothelial

\section{cells- lined cyst}

For high-risk patients, a non--operative strategy may be followed. The longest reported follow-up lasted twenty five years, and yielded a $2.5 \mathrm{~L}$ cyst at the time of resection. Aspitions for resection of pericardial cystas include large malignant potential, and prevention of the life threateing emergencies. While the morbidity and mortality of pericardial cysts are unknown, surgery has been demonstrated as the only definitive cure. Since operative risks of minimally invasive techniques are exteremely low, it would seem reasonable to offer resection for all pericardial cysts in otherwise healthy patients for whom the risk of surgery is low.

\section{ACKNOWLEDGEMENTS}

The authors acknowledge late MR. Bhim Bahadur Tamang who sacrificed his life for medical education and Mr. Ashok Bansari for his help during computer printing 


\section{REFERENCES}

1. Yuzi Milyamoto, Kenzi Onishi, Masataka Mitluno, et al. Ann Thorac Cardiovasc Surg 2003;Vol 9, No 6, 389-393.

2. Cohn LH, Edmunds LH Jr. eds, Cardiac Surgery in the adults. New york: Mc Graw-Hill, 2003: 401-412.

3. Swain JA, Mc Donald TJ Jr, Grififth PK, et al: Low flow hypothermic cardiopulmonary bypass protects the brain. J Thorac Cardivasc Surg 1991;102: 76.

4. Svensson LG, Crawford ES, Hess KR, et al. Deep hypothermia with circulatory arrest. Determinants of sroke and early mortality in 656 patients. J Thorac Cardiovasc Surg 1993;106:19-28.

5. Koselli JS, Buket S, Djukanovic B. Aortic arch operation: current treatment and results. Ann Thorac Surg 1995;59:19-27.

6. Okita Y, Minatoya K, Tagusari O, et al. Prospective comparative study of brain protection in total aortic arch replacement: deep hypothermic circulatory arrest with retrograde perfusion or selective antegrade cerebral perfusion. Ann Thorac Surg 2001;72:72-79. 